\title{
Boleswana Educational Research
}

\author{
Mickey Anderson \\ Molepolole College of Education, Molepole - Botswana .
}

\begin{abstract}
Stakeholders, educators and learners increasingly perceive distance education as an effective knowledge system. Diploma in Education by distance mode aims at upgrading all primary school teachers to the diploma level. It is expected that the Diploma in Primary Education (DPE) programme will improve teachers' knowledge skills and competency in primary education at the foundation level. One of the specialist areas is English. Four modules in English are offered for the DPE through Distance Education in Botswana. Each module covers the three main components: language, literature and methodology. Even as policy makers continue to build on the knowledge system, data about printed materials for the DPE raise some vital concerns pertaining to efficiency and effectiveness of materials. The purpose of this research paper is, therefore to investigate the effectiveness of this module to learners' knowledge and competency in English. The findings of the study reveal that the materials are effective to some extent. It has been recommended that Module I be reviewed for improved effectiveness.
\end{abstract}

\section{Introduction}

Since the mid twentieth century correspondence courses were offered by the United Kingdom, United States of America, Australia and India. Institutions, from which these courses originated, included the Rapid Results College, International Correspondence Schools Inc. and others. These courses are part of a knowledge system used to present appropriate information, ideas, facts and skills across the spectrum of vocational, practical and academic subject areas, and across educational levels.

Distance Education is increasingly used in teacher education in developing and developed countries. It has the potential to strengthen and expand the teaching of the twenty-first century and to help achieve the target of education for all by 2015 (Robinson and Lathem (eds.) 2002 .

Hence Botswana's document, Vision 2016 gives prominence to education. Certainly, Distance Education is one of the programmes that will help 
Botswana's Vision 2016 become a reality. Akinpelu (1998) informs that Botswana's plan was:

To expand and reinvigorate the Distance Education Unit of the University of Botswana's Centre for Continuing Education, all these are evidence that Distance Education is now accepted as indispensable if the nation will be enabled to cope with the rapidly expanding education system.

For the expansion to be realized, certain considerations were made. To develop and produce new courses in a distance teaching style would prove to be too time consuming and expensive. Therefore, the decision was taken to implement the courses that were already approved. However, it is to be noted that writing successful course materials for distance teaching and learning requires special expertise. Among other requirements, the materials must go beyond compiling a series of lecture notes and content must not be overloaded for the distance learner, consequently it was necessary to plan, analyse and apply the instructional content being taught.

In education and training, Botswana has adopted the distance education mode to address the significant need for upgrading and training of teachers for the Diploma in Primary Education. This training is done through print as educators develop and produce learning and teaching materials for delivery of content. The tutees are given modules in text to read and complete their assignments at home.

Most of the trainees that were selected in December, 2002, for training are in possession of the Botswana Certificate Education (at the end of Form 3 -Community Junior Secondary School). Others had completed schooling at seventh standard. This study, therefore, seeks to ascertain the effectiveness of the printed materials currently used to teach English by distance Education.

\section{Background to the problem}

The Diploma in Primary Education Programme has replaced the Primary Teacher Certificate (PTC) Programme that had some limitations. The Centre for Continuing Education in collaboration with the University of Botswana was requested, "to develop modules which can be delivered, that has the same content as the full-time programme offered at the four colleges of primary education". (Rathedi 1997:52)

\section{Rationale}

The researcher of this study decided to carry out this investigation after the distant education tutees complained that the content in English Module I for 
the Diploma in Primary Education was difficult. Many years has elapsed sine they had been students in the classroom and they could remember very little about grammar and poetry. In addition there was too much reading to be done and as a result too much content to absorb as full time employees. Hence this study has been undertaken to investigate the effectiveness of the printed materials used to deliver content in English for the Diploma in Primary Education.

\section{Statement of the problem}

Although the DPE students are senior teachers and head teachers they lack a higher degree of proficiency in the use of the English language. Since 1999, when English for distance education was introduced for the Diploma in Primary Education Programme in Botswana, it was taught to a great extent, using English language teaching materials the conventional way. These materials have been "adopted" and "adapted" to reflect the assumed "content" of English, the Distance Education style. In cases where wholesale "adoption" of English language teaching materials for distance teaching $\backslash$ learning has been done, candidates' resentment for some of the materials has been noted with comments such as "When am I going to read this whole book?" "I've finished schooling so long," being expressed at the short periods of face-to-face tutorials.

\section{Research questions}

The study addressed the following main question:

- To what extent has the use of printed materials been effective in teaching English by distance education for the Diploma in Primary Education (DPE) Programme?

Related to the above major question are the following sub questions:

i) How have the tutors in the DPE used the printed material to impart knowledge in English language to tutees?

ii) How well have tutors of DPE used their teaching skills to help tutees develop proficiency in English?

iii) How well have tutees performed in the DPE Module 1 English course?

\section{The role of English in Botswana}

The official language in Botswana is English and is also deemed a second language (L2). According to the language policy as articulated in Botswana's Revised Policy of Education (RNPE 1994: 59) "The medium of instruction shall be English from Standard five onwards. Then it is crucial 
for teachers, moulders of the nation, to be proficient in the use of the language". Judd (1987:1) argues that:

The socio-political environment in which English language instruction occurs has a direct impact on the shape of TESOL instruction. Failure to consider these socio-political factors can lead to dire consequences for all those involved.

In addition, the National Commission emphasises that "the crucial importance of English competence (reading, writing and speaking) not only for further academic study, but also as a preparation for work and adult life".

Surely, these senior teachers and head teachers, to function effectively in the educational context in which English is the medium of instruction, need to learn and greatly master the English language. The learning of English does not only relate to the subject itself but to all subjects across the curriculum. Subjects like Social Studies, Science and Foundations of Education require the utilization of English by which learners will achieve credibly in their performance. Judd (1987:3) postulates that: "Language policy has a direct impact on TESOL instruction and therefore should be considered as a crucial factor in planning TESOL programme.

\section{Definition of terms}

- Distance Education has been described as a mode of knowledge system when teacher and learner are divided by physical distance, voice and print. Very little face-to-face interaction is used to bridge the instructional gap. Disadvantaged youth and adults alike, though by limited time, qualifications, distance or physical disability can be provided with further education and qualification. According to Moore and Thompson (1990); Verduin and Clark (1991):

teaching and studying at a distance can be as effective as traditional instructional instruction, when the method and technologies used are appropriate to the instructional tasks, there is student-to-student interaction, and when there is timely teacher-to-student feedback.

- Print is one of the critical knowledge systems in distance education practice. Print formats include textbooks, study guides, workbooks, course syllabi and case studies. 
- Knowledge System has been defined as a knowledge tool. It has also been stated that "human intelligence requires the ability to move smoothly from one thought to another". Therefore, printed materials, the most used in DPE have to be flowing. The information has to be organized; to be remembered and managed. Also, careful attention has to be given to the structuring and designing of the materials by educators.

- Learners, students, tutees are used interchangeably.

- Trainers, educators, tutors are used interchangeable.

Learners, however, experience a number of problems including isolation, inability to understand concepts dealt with in the course materials. There is need no doubt that distance educators need to be more flexible and interactive in writing distance education content. This presents enormous challenges to the distance trainer whose knowledge and skills have to stretch to the limits to develop materials that suit the diverse learners' needs on one hand and histher teaching style on the other. However, it is to be noted that most distance educators on the whole, and specifically those who teach English are accustomed to their materials in the form of textbooks. But as new technology is advanced, these educators will explore other modes than print.

\section{Profile of the distance learner for the DPE programme}

The primary role of the student is to learn. In a distance education setting, the process of student learning is more complex for several reasons:

- Demographic factors - large numbers, age range of 30-55 years; residing in urbanไrural areas.

- Motivation - opportunity has presented itself for further qualifications, job mobility and improved salaries.

- $\quad$ Subject Background - learners' qualifications consist of (a) COSC; (b) Primary Lower; (c) JC $\backslash$ PTC; (d) PH; (e) Elementary Teachers Certificate which is set at the generalist level - not too detailed as the specialist. $90 \%$ of the candidates are holders of JC\PTC.

- Professionally, these learners are head teachers, deputy head teachers, senior teachers, senior teachers II, teacher grade I, teacher grade II.

- Some do not have adequate resources e.g. lack of electricity, any proper lighting, and inadequate library facilities.

- Typical problems to be noted - family problems, illnesses, need for study skills. 
However, in spite of the limitations stated above, distant learners are expected to work independently to keep up with lectures, assignments to read selectively and pass examinations. Undoubtedly, academic reading presents problems and challenges for many distant learners.

Academic reading is one of the fundamentals for study in higher learning. It involves interacting with the text, questioning, anticipating, predicting, exploring, contextualizing and problem solving. It requires one to analyse what is written in books, to explore, to discover and to make adequate use of the reference material, as well as gain information from all types of printed media. The challenge then for DPE trainers is how to help learners to overcome their difficulties in reading.

The distant learners in Botswana are second language learners and have expressed despair and a sense of hopelessness in their performance in the English for DPE as they "have been shown repeatedly to lag behind in their reading" (Edwards (1993:100) in Anderson and Umunnakwe (2001:3) Effective and proficient reading of materials for the study of the subject, English is crucial to distant Education. Learners.

A two-day Distance Education workshop was held in December, 2002 at the University of Botswana to address the need for well-trained DPE tutors. At this workshop the areas of emphasis were establishing the importance of the distant educator in English; the necessity for preparation of meaningful and adequate content. In order to impart knowledge effectively to the learners, the DPE tutor has to consider the approaches and strategies for successful learning. The selected instructional mode is vital since many of the learners have lamented the fact that they had not been students for several years; and that they had found the 'new' learning situation traumatic.

\section{Developing knowledge systems using printed materials}

The print in the Diploma Programme in Education distance education mode should provide self-learning materials. Undoubtedly, print is the foundation of distance education programmes and the basis from which all other knowledge systems are built.

However, both educator and student will need to access supplementary materials in order to enhance the basic textbooks, study guides, workbooks, course syllabus, case studies and assignment booklet. These various formats of printed materials have proven advantageous in their spontaneous presentations, instructional transparency, easy to use, easy to review and reference and coat effective. Nevertheless, occasionally it is useful and beneficial to enhance printed materials. This can be done in several ways which include work cards, other related texts, handouts, and the use of transparencies and Overhead Projector. Indeed, "use of effective printed materials also require levels of appropriateness and quality of feedback as learners learn by doing (Race, 1998:10). 
Figure 1 shows how the different components of distance education are interrelated. Each component is vital for effective teaching and learning via distance

\section{Fig. 1: DEVELOPING KNOWLEDGE SYSTEMS USING PRINTED MATERIALS}

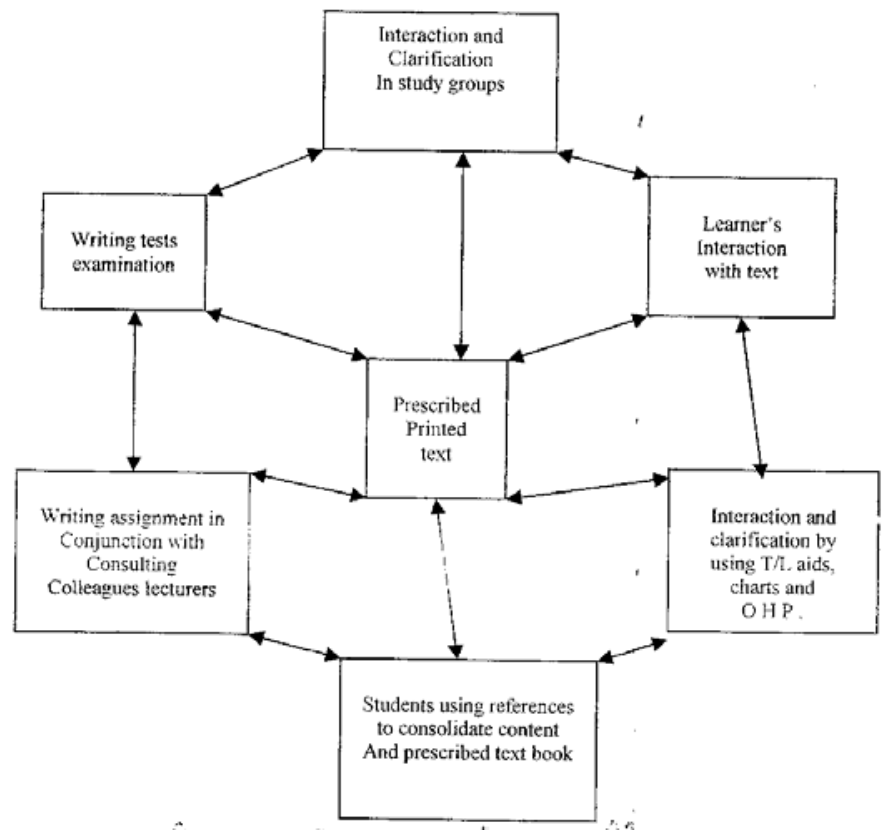

Module 1

Since the learners are experienced practitioners in the primary schools, but need improved proficiency in English language content, Module 1 (a textbook) was designed. This module focuses on the eight parts of speech, spelling, comprehension, composition writing, language development, language acquisition and poetry. The aim is to help learners to be more proficient, accurate and confident in their own use of the English language as they teach it to their pupils (Sibanda and Binns, 1999:1). An attempt has been made to produce a user-friendly text. However, there are aspects of the conventional whereby elements of interaction are missing e.g. the conversational tone or dialogue. The insertion of graphs and charts in a text helps the material to be appealing, interesting and informative. However 
Module 1 has very few graphics. Surely the presentation of "solid print" in 211 pages can be daunting to the heavily pressed student.

An assignment booklet has accompanies the module. In this booklet there are two assignments to be done before tutees write a test and an examination.

Another area for attention by the distance educator is his the distant learners to develop the necessary study skills that could make them independent and self-directed learners. One such study skill is academic reading. Needless to say, the year one distant learners needed skills and techniques to cover the volume of material to study the English Module 1 from January 2003 to August 2003 (8 months). They needed extensive vocabulary development, syntactic pattern recognition and semantic relationships. Of note is that the reader had in the processing of strategies changed to meet the demands of the text and the purpose of reading. Also, a good understanding of the layout and structure of a text, could help in easy access to useful information embedded therein, and make reading more efficient.

Some of the reading techniques students need involve skimming, scanning, the SQ3R technique, analysis of the organisation of text and understanding graphic presentation. The emphasis will then shift from WHAT learners CAN DO to HOW they CAN DO IT (in reading).

\section{Methodology}

The research design

This was a survey study using qualitative and quantitative data to ascertain how effective English Module 1 has been in its printed form in the teaching and learning by distant learners.

\section{Population and sample}

The population for the study was 27 male and female tutors and 69 male and female tutees. The population speak Setswana as their first language and English as a second language. In some cases English may even be a third language. The sample also included tutors whose first language is English.

The sample comprised 15 distant educators who were engaged in teaching the Diploma in Primary Education English course to students from Lobatse and Tlokweng Primary Colleges of Education. The tutors are from Molepolole College of Education, and from Tlokweng and Lobatse, the two primary colleges where conventional teaching of English is done.

\section{The instrument}

The instrument for data collection was a questionnaire constructed by the researcher. It was administered to the sample. The questionnaire had two sections. The first section focused on the demographic profile of trainers 
while the second dealt with the effectiveness of their orientation to the DPE English module, and the impact trainers' contribution made to the teaching and learning of the English course. Then the researcher conducted interviews with 9 tutors who formed $47 \%$ of the subjects in the sample.

Data analysis and discussion of results

At least $94 \%$ of the questionnaires were returned and analysed.

Table 1: Distant trainers' Responses to Questionnaire: Section 1

\begin{tabular}{|l|c|c|}
\hline & No. & $\%$ \\
\hline MCE trainers & 8 & 53 \\
\hline Lobatse trainers & 4 & 27 \\
\hline Tlokweng trainers & 3 & 20 \\
\hline Lecturer 1 & 7 & 47 \\
\hline Senior lecturer I & 5 & 33 \\
\hline Senior lecturer 1 & 3 & 20 \\
\hline
\end{tabular}

Table 1 presents the number of trainers who formed the sample in the study, and the percentage from each training institution. It is evident that the majority of trainers (53\%) were attached to Molepolole College of Education (MCE), the host institution. Of note, is that the greatest percentage is at the lecturer 1 position.

Table 2: Sample trainers

\begin{tabular}{|l|c|c|c|c|c|}
\hline Sample Trs. & $1-3$ yr. & $4-6$ yr & $7-9$ yr & $10-12 \mathrm{yr}$ & 13 yr\& over \\
\hline $\begin{array}{l}\text { Years as a } \\
\text { teacher trainer }\end{array}$ & 3 & 5 & 1 & 3 & 3 \\
& $20 \%$ & $34 \%$ & $6 \%$ & $20 \%$ & $20 \%$ \\
\hline
\end{tabular}

In table 2 , it is readily seen that trainers are experienced practitioners in the field of teaching. Interestingly enough, the highest percentage is for those who have $4-6$ years experience.

Table 3: Trainers taught on a Distance Education Programme before

\begin{tabular}{|l|l|}
\hline Yes & No \\
\hline 3 & 12 \\
\hline $20 \%$ & $80 \%$ \\
\hline
\end{tabular}

Table 3 shows that only 20 percent of trainers had previous experience at teaching distance education. This is quite remarkable. 
Table 4: Utilisation of materials/teaching skills to help tutees' proficiency in English

\begin{tabular}{|l|c|c|}
\hline $\begin{array}{l}\text { Materials/teaching skills used in lesson } \\
\text { delivery }\end{array}$ & No. of trainers & \% of trainers \\
\hline The textbook only & 3 & 20 \\
\hline In addition to textbook: recommended books & 6 & 40 \\
\hline Work sheets & 3 & 20 \\
\hline Chalkboard & 15 & 100 \\
\hline In class role play & 4 & 27 \\
\hline Group \& individual presentations & 8 & 53 \\
\hline Telephone discussions & 3 & 20 \\
\hline
\end{tabular}

Table 4 refers to research sub-questions:

i) How have tutors in the DPE used the printed material to impart knowledge in English language to tutees?

ii) How well have tutors of DPE used their teaching skills to help tutees develop proficiency in English?

The consensus of perception by tutors was that the module adequately covered all the language skills and it captured principles of the communicative approach to language teaching and learning. However, it does not cover adequate ground on literature as a language-learning tool. It was suggested that there should be an input of literature material rather than concentrating so much on poetry in this first module of four.

Table 5: Tutees’ Performances at Test and Examination

\begin{tabular}{|c|r|r|r|r|}
\hline Score ranges & \multicolumn{2}{|l|}{ No. of tutees } & \multicolumn{2}{c|}{$\%$ of tutees } \\
\hline & \multicolumn{1}{|c|}{ Test } & \multicolumn{1}{|c|}{ Exam } & \multicolumn{1}{c|}{ Test } & Exam \\
\hline $100-90 \%$ & 0 & 0 & & \\
\hline $89-80 \%$ & 6 & 8 & $29 \%$ & $42 \%$ \\
\hline $79-70 \%$ & 5 & 3 & $24 \%$ & $16 \%$ \\
\hline $69-60 \%$ & 6 & 5 & $29 \%$ & $26 \%$ \\
\hline $59-50 \%$ & 3 & 3 & $14 \%$ & $16 \%$ \\
\hline $49-40 \%$ & 1 & 0 & $4 \%$ & - \\
\hline Total & 21 & 19 & & \\
\hline
\end{tabular}

Table 5 shows that tutees performed well in both test and examination at the end of the module. Even though tutors felt incompetent to teach the module effectively, they managed successfully. Also, it would seem that the employment of materials and teaching skills in addition to using the Module 1 only, enhanced students' performance. This table certainly points to answering the third research sub-question, that is, "How well have tutees performed in the DPE Module 1 English course?" 
The respondents' experience in the teaching field ranged from one year to fifteen years. Of the respondents $80 \%$ had never taught a distance education programme before. Although the majority of the respondents found the two-day workshop beneficial and insightful, it was their view that it was an inadequate orientation into the DPE programme. Most of the respondents are teaching at the secondary college of education (MCE) and are not familiar with the operation of the primary college, thus being unfamiliar with the behaviour of the primary college student. They also expressed insufficient knowledge of the needs and characteristics of the adult learner.

\section{Conclusion and recommendations}

The research paper has attempted to analyse the efficiency and effectiveness of using Module 1 in print for teaching and learning English in the DPE programme. The general consensus by respondents to the questionnaire and interview was that Module 1 represented "a strong print component ... in the form of a course text, as well as readings ...". http://www.uidaho.edu/eo/dist/.html. The conclusion was that the module was effective.

In light of the discussion on building knowledge systems by the distance education mode, the following recommendations are pertinent:

- Distant trainers should encourage students as much as possible to apply reading strategies and techniques to ensure effective reading and comprehension of materials in the English module.

- There is need for the inclusion of an interactive audio or voice-tovoice interaction approach in addition to the printed material.

- Tutors should make a great effort to use support materials such as the overhead projector, power point for the enhancement and effective use of the printed material.

- Tutors should undertake a course on, "Psychology of Adult Learning".

- DPE tutors should familiarize themselves with supplementary materials be they in the library or Internet so as to give necessary and appropriate references to learners.

- It is important to help keep learners focused. Therefore, the DPE trainer should make every effort to teleconference/e-mail learners as timely feedback on their performance is given.

\section{References}

Akinpelu J.A. (1995). "Teacher Education: The Key to Continuous School Improvement - by Patty Swarts: A Response". In Improving Education 
Quality for Effective Learning: The Teacher's Dilemma. Gaborone: Ministry of Education.

Judd, E.E (1987)."Language Policy, Curriculum Development and TESOL Instruction: A Search for Compatibility". In Sibanda, O. (1992) "The Influence of English on Pupils' Performance in Mathematics, Social Studies and Science". An Unpublished Dissertation.

Moore, M.G. and Thompson, M. M. with Quigley, A.B., Clark, G.C., and Goff, G.G. (1990). The Effects of Distance Learning: A Summary of the Literature. Research Monograph No.2 University Park, P.A. Pennsylvania State University, American Center for the Study of Distance Education

(ED330

321).http://www.uidaho.edu/co/distl.html.(retrieved on 09/06/2003).

Race, Phil (1998). 500 Tips for Open \& Flexible Learning. London: Kogan Page Limited.

Rathedi, M. (1997). *Raising the Quality of Teacher Preparation and Recent Trends in Teacher Education". In Improving Education Quality for Effective Learning: The Teacher's Dilemma. Gaborone: Ministry of Education.

Revised National Policy on Education (1994). Government Paper No.2. Gaborone, Botswana: Government Printer.

Robinson, B. and Latchem, C (eds) (2002). Teacher Education Through Open and Distance Learning. London: Routledge - Falmer Press http://www.col.org/worldview/ (retrieved on 09/06/2003).

Sibanda, O. and Binns, J. (1999), Diploma in Primary Education English 1. Gaborone: University of Botswana and Ministry of Education.

Umunnakwe, N.E. \& Anderson, M. (2003). "The Reading Proficiency of Firet Year Teacher-trainees at Molepolole College of Education: A Challenge for Teacher-trainers and Sustainable Development". Unpublished Research Paper

Verduin, J.R. \& Clark, T.A. (1991). Distance Education: The Foundations of Effective Practice. San Francisco, C.A: Jassey - Bass Publishers.http://www.uidaho.edu/co/distl.html. (retrieved on 09/06/2003). 